\title{
A Representatividade Feminina e o Exercício da Docência no Ensino Superior
}

\author{
Elda Alvarenga ${ }^{1}$ \\ Erineusa Maria da Silva ${ }^{2}$ \\ Ileana Wenetz ${ }^{3}$
}

\section{Resumo}

Este artigo tem como objeto de estudo a representatividade das mulheres no processo do trabalho docente no ensino superior. Visa a investigar como as mulheres são contempladas em relação à representatividade feminina em seu exercício docente na Universidade Federal do Espírito Santo. Apoia-se em pesquisas sobre gênero em articulação com estudos do trabalho docente. Valeu-se de uma pesquisa de campo exploratória que buscou, sob o paradigma indiciário, levantar informações da representatividade feminina na instituição pesquisada. Conclui que, apesar de as mudanças e os deslocamentos serem bastante lentos, nas três categorias analisadas, foi possível perceber avanços importantes na direção da equidade de gênero.

\section{Palavras-chave}

Representatividade feminina. Docência. Ensino superior.

\section{Abstract}

This article aims to study the representativeness of women in the process of teaching work in higher education. It aims to investigate how women are contemplated in relation to female representation in their teaching exercise at the Federal University of Espírito Santo. It is based on research on gender in conjunction with studies of teaching work. We used an exploratory field research that sought, under the scientific paradigm, to raise information about female representation in the institution surveyed. It concludes that, although the changes and displacements are quite slow, in the three categories analyzed, it was possible to notice important advances in the direction of gender equity.

\section{Keywords}

Female representation. Teaching. Higher Education.

\footnotetext{
${ }^{1}$ Doutora em Educação pela Universidade Federal do Espírito Santo. E-mail: eldaalvarenga@uol.com.br.

${ }_{2}^{2}$ Doutora em Educação pela Universidade Federal do Espírito Santo. E-mail: erineusams@yahoo.com.br.

${ }^{3}$ Doutora em Ciências do Movimento Humano pela Universidade Federal do Rio Grande do Sul. E-mail: ilewenetz@gmail.com.
} 


\section{Mulheres no ensino superior}

Este artigo é fruto de um estudo que vimos desenvolvendo desde o ano de 2018, por ocasião da realização da $1^{a}$ Conferência de Ações Afirmativas da Universidade Federal do Espírito Santo (Ufes). Na época da realização desse evento, foi-nos encomendado um texto-base no qual dedicássemos nosso olhar à condição das mulheres (professoras, estudantes e funcionárias) na Ufes com o objetivo de, a partir daí, pensarmos coletivamente, durante a conferência, propostas de políticas afirmativas de gênero para esse grupo. Assim, realizamos um levantamento de dados em algumas Pró-Reitorias4 da Ufes, no site da Ufes, no site da Associação dos docentes da Ufes - Seção Sindical do Andes/ES (Adufes) e informações publicadas na revista da Ufes e da Adufes.

Com base nesse estudo inicial, sentimos necessidade de nos debruçarmos mais detidamente sobre a temática e analisar como se dá a representatividade das mulheres na Ufes ${ }^{5}$ no exercício da docência. Nesse sentido, algumas questões movimentaram esta investigação: quantas mulheres ocupam o magistério superior na universidade? Em que cursos? Em que proporção, em relação aos homens, as mulheres desenvolvem funções de chefia de departamentos, coordenações de colegiados, direção de centros e coordenação de grupos de pesquisa? Interessa-nos, assim, relacionar a condição docente com as relações sociais de gênero e refletir sobre a representatividade feminina ${ }^{6}$ na universidade e sobre o reconhecimento do trabalho docente feminino no ambiente acadêmico.

Com esse objetivo, retomamos os dados já produzidos e avançamos na produção de outros, de forma a apresentar uma "fotografia" das relações

\footnotetext{
4 A recolha de dados foi realizada nas seguintes Pró-Reitorias da Ufes: de Administração, de Graduação, de Pós-Graduação e a Pró-Reitoria de Assuntos Estudantis e Cidadania (Proaeci).

${ }^{5}$ Neste texto, por questões de recorte, falaremos das professoras sem tratar de forma detida sobre as estudantes e as funcionárias. Por falta de dados nas fontes obtidas na universidade, vamos focar as mulheres sem considerar suas orientações ou identidade de gênero. No entanto, sabemos, por fontes "informais", que não temos professoras trans na universidade, apenas algumas poucas funcionárias assim se apresentam. Essa questão fica como agenda de pesquisa até para pensar esse recorte incluindo as alunas também.

${ }^{6}$ A noção de representatividade feminina é aqui compreendida, nos termos de Bobbio, Matteucci e Pasquino (1998), como a expressão dos interesses de um grupo (político-partidário, de movimento social, de classes etc.) na figura do/a representante que, ao falar, representa um coletivo porque o faz com compromisso às demandas daqueles/as que representa. Mas, fundamentalmente, a representatividade, nesse processo, é também parte da formação subjetiva e identitária do que se torna/é a pessoa que faz parte desse grupo.
} 
sociais de gênero a partir da análise da presença das mulheres e sua representatividade na Ufes, em termos quantiqualitativos.

Nesse movimento, consideramos alguns elementos do método indiciário de pesquisa por enfatizar as particularidades dos processos analisados a partir de indícios e "pistas" deixados no tempo. O método entende a realidade como "[...] fundamentalmente descontínua e heterogênea" (GINZBURG, 2007, p. 269). Nessa perspectiva, no trabalho com as fontes, ganham relevância desde o documento mais improvável até aquele que se configura como "excepcional normal". Em última análise, partimos do pressuposto de que, por mais anômalo que seja, qualquer documento pode ser lido no conjunto de uma série. Mais do que isso, "[...] pode servir, se analisado adequadamente, a lançar luz sobre uma série documental mais ampla" (GINZBURG, 2007, p. 263).

Do ponto de vista teórico-metodológico, apoiamo-nos nos estudos de gênero numa perspectiva consubstancial. Entendemos que gênero deve ser compreendido como um significado social e político, historicamente atribuído aos sexos (SCOTT, 1995). Esses significados são capazes de evidenciar as dissimetrias e hierarquias que se expressam nas relações e práticas sociais. Compreendemos que as relações de gênero estão presentes em todas as práticas sociais dos humanos compondo com as relações de classe e as relações étnicoraciais uma alquimia estruturante da sociedade, o que nos leva a considerar que as análises sociológicas, em especial no campo educacional feminizado, não podem prescindir de uma análise de gênero. Desta forma, gênero colocase como uma categoria importante de análise das relações e práticas sociais exercitadas no campo educacional.

Nesse sentido, é fundamental tratar a questão de gênero como imbricada consubstancialmente $^{7}$ à categoria classe social e étnico-racial, ou seja, compreender a existência de uma unidade indissociável (HIRATA, 2014) entre gênero, raça/etnia e classe. Essa compreensão, segundo Hirata (2014, p. 61), complexifica "[...] a noção mesma de 'conhecimento situado'8 $[\ldots]$, pois apresenta a possibilidade de existência de dissimetrias no que tange à posição

\footnotetext{
7 Hirata (2014) faz uma importante distinção entre os conceitos de consubstancialidade e interseccionalidade. A autora afirma que a noção de interseccionalidade (CRENSHAW, 2002) visa, de forma mais enfática, à intersecção entre sexo e raça, deixando mais invisibilizada a classe social; enquanto a noção de consubstancialidade (KERGOAT, 2010) visa a uma imbricação entre sexo, classe e raça/etnia, o que fatalmente traz implicações tanto teóricas como políticas com significativas diferenças.

8 A noção de "conhecimento situado" ou "parcial" denuncia que as definições vigentes (de neutralidade, objetividade, racionalidade e universalidade da ciência) frequentemente incorporam uma visão de mundo masculina, ocidental, da classe dominante e branca (HIRATA, 2014).
} 
de poder nessas relações, por exemplo, nas relações de classe e gênero ou nas relações de raça e de gênero". Nesse sentido, as relações de gênero no magistério implicam especificidades quanto ao exercício docente que merecem ser analisadas considerando essa consubstancialidade.

Importante destacar que, quando falamos no trabalho docente, estamos nos referindo às complexidades que envolvem o trabalho docente e não apenas ao trabalho pedagógico. $\mathrm{O}$ trabalho pedagógico, especialmente o aspecto didático a ele inerente, apesar de ser uma parte bastante significativa do processo, não deve ser compreendido como sinônimo de trabalho docente, que deve ser tomado como aquele que envolve "[...] formas mais amplas de organização e gestão do trabalho coletivo" (HYPOLITO, 2010, p. 1). Assim, compreendemos que, além do ensino, outras atividades desenvolvidas por professores e professoras no ensino superior (gestão, pesquisa, extensão, por exemplo), estão afetos à universidade e compõem o cenário do exercício docente.

Como amplamente sabido, o trabalho docente se constitui como majoritariamente feminino - feminilizado (YANNOULAS, 2013b). Ademais, Yannoulas (2013a) acompanhada de diversas outras autoras (MARCONDES, 2013; CARRILHO, 2013; OLIVEIRA, 2013; LOMBARDI, 2013), em estudo publicado em 2013, já afirmavam ser cada vez mais evidente o fenômeno da feminização das ocupações e das profissões. Yannoulas (2013b) aponta uma distinção fundamental entre a feminilização e a feminização. A feminização inclui, mas expande a feminilização, pois, além de descrever a entrada das mulheres nos mercados de trabalho, também intenta explicar as motivações e efeitos dessas inserções, trazendo à tona seu caráter ambíguo e contraditório. Portanto, ademais de ser uma distinção de ordem metodológica, também é, fundamentalmente, de ordem política.

Apesar de perceberem a feminilização das profissões, o que representa os avanços alcançados pelas mulheres, essas autoras chamavam a atenção para a persistente desigualdade de gênero que se mantinha por percursos sexuados associados não raramente à naturalização das habilidades ou capacidades femininas.

Confirmando essa persistência, um estudo recente do Instituto Brasileiro de Geografia e Estatística (2018), intitulado mulheres no mercado de trabalho, demonstra que as desigualdades entre homens e mulheres no mercado de trabalho, ainda que com deslocamentos, mantêm-se por ramos de atividades. Da mesma forma, em uma matéria publicada pela revista Mátria da Confederação Nacional dos/as trabalhadores/as da Educação (CNTE), intitulada Elas sabem mais, mas ainda ganham menos (MÁTRIA, 2015), afirma- 
se que, apesar de as mulheres, no geral, terem maior escolaridade, experiência e demonstrarem maior produtividade que os homens, elas ainda recebem os menores salários. A matéria cita o Relatório sobre Salário Global da Organização Internacional do Trabalho (OIT), o qual aponta que "[...] homens recebem mais do que as mulheres em todos os 38 países analisados, mostrando que a distância de gêneros, quando se trata de proventos, prevalece no mundo inteiro" (MÁTRIA, 2015, p. 35).

Essas desigualdades podem ser percebidas nas dissimetrias e nas hierarquias expressas, não somente na diferença salarial entre homens e mulheres que exercem as mesmas atividades laborais. Podem também ser notadas na ainda reduzida representatividade político-partidária das mulheres na sociedade, apesar da existência de leis de cotas, ${ }^{9}$ nos cargos de liderança nos serviços públicos e privados, nos sindicatos, nas escolas, nos partidos políticos e nas dificuldades de mulheres participarem de territórios laborais ocupados historicamente por homens dentre outras (YANNOULAS, 2013a).

Outro indicativo da persistência da desigualdade assinalada pelo sexo, ${ }^{10} \mathrm{e}$ que se revela uma das marcas mais perversas das sociedades que se nutrem de uma cultura patriarcal, são as diversas violências (sexuais, físicas, psicológicas, patrimoniais ou morais) que são empreendidas contra as mulheres cotidianamente. ${ }^{11}$

Com foco na análise da reinserção das mulheres nos mercados de trabalho no Brasil recente, Gomes (2012) ressalta que, se, por um lado, é evidente o crescimento do número de mulheres que ocupam espaços nos mercados de trabalho nas últimas décadas em comparação com os homens; por outro, o aumento da ocupação das mulheres vem acompanhado da elevação da

\footnotetext{
${ }^{9}$ A Lei ${ }^{\circ}$ 12.034/09 tornou obrigatório o preenchimento do percentual mínimo de $30 \%$ para candidaturas femininas, o que contribuiu para um aumento expressivo do número de candidatas mulheres em relação aos anos anteriores. No entanto, o número de mulheres eleitas não aumentou na mesma proporção. Além disso, a Lei ${ }^{\circ} 13.165 / 15$, acompanhada da Emenda Constitucional $n^{\circ}$ 97/17, buscou maximizar a eficácia da política de cotas, vinculando as candidaturas de mulheres ao investimento partidário nas eleições.

${ }^{10}$ Os dados obtidos na Ufes ainda são apresentados como marcadores de sexo. Nossa perspectiva baseia-se na categoria gênero, pois optamos por tensionar o sentido tradicional que o sexo carrega.

${ }^{11}$ A Lei $n^{\circ} 11.340 / 06$, que cria mecanismos para coibir a violência doméstica e familiar contra a mulher, nos termos do $\S 8^{\circ}$ do art. 226 da Constituição Federal, da Convenção sobre a Eliminação de Todas as Formas de Discriminação contra as Mulheres e da Convenção Interamericana para Prevenir, Punir e Erradicar a Violência contra a Mulher, dispõe sobre a criação dos Juizados de Violência Doméstica e Familiar contra a Mulher, altera o Código de Processo Penal, o Código Penal e a Lei de Execução Penal e dá outras providências.
} 
precariedade nas relações de trabalho. Para o autor, os dados oficiais revelam uma importante contradição, qual seja:

[...] as mulheres constituem a maioria da população ocupada com faixa de remuneração de até 1 Salário Mínimo. Mas, à medida que se elevam os patamares salariais, a população masculina vai ganhando maior colocação, até se tornar expressivamente majoritária (pouco acima de 80\%) nas faixas de maior remuneração [...]. (GOMES, 2012, p. 143).

O processo de inserção das mulheres no magistério, como profissão no Brasil, tem íntima relação com esses dados, tendo em vista estar alinhado aos pressupostos de gênero da sociedade brasileira, nitidamente vinculado a uma cultura patriarcal e sexista Como nos lembra Ribeiro (2011), a tradição ibérica transportada de Portugal para a Colônia preconizava que as mulheres não necessitavam ler e escrever, por isso a educação a elas ofertada limitava-se aos trabalhos domésticos, pois essa tradição "[...] considerava a mulher um ser inferior. O sexo feminino fazia parte do imbecilitus sexus, ou sexo imbecil" (RIBEIRO, 2011, p.79).

Alvarenga (2018) questiona os processos que possibilitaram a inclusão das mulheres na profissão e considera que essa inserção se vincula, de modo indissociável, à expansão da instrução básica para ambos os sexos, na medida em que, para atender aos padrões sociais do início do século XIX, as mulheres foram chamadas para exercer a docência para as meninas, ao mesmo tempo que, devido à carência geral de professores normalistas, a sua presença se fez necessária também em classes mistas. Dessa maneira, a ampliação do acesso das meninas à escolarização abriu a porta para a presença crescente das mulheres no magistério, impulsionando a atuação feminina no Curso Normal, o principal instrumento de formação e habilitação para os professores e as professoras no final do século XIX e início do XX.

Nessa linha de raciocínio, Alvarenga (2018) aponta que a inserção das mulheres no magistério se deu inicialmente na instrução primária, posteriormente no ensino secundário e, somente muitos anos depois, no ensino superior. Para a autora, apesar de a Igreja Católica ter se posicionado inicialmente contra a educação escolar das meninas, houve todo um movimento dessa instituição para influenciar os processos educativos destinados às meninas da instrução primária e às normalistas. Durães (2002) destaca a influência da Igreja Católica na associação, muito presente na virada do Oitocentos para o Novecentos, entre a função docente e a abnegação, missão 
e vocação. Vale lembrar, nesse contexto, o que nos indica Nascimento (2011, p. 99):

[...] a despeito do caráter eminentemente conservador da Igreja Católica, em relação às mulheres, certamente, suas ações contribuíram para o alargamento do campo de atividade delas. Algumas mulheres souberam usufruir dessa influência e continuaram vivendo, correspondendo ou não aos padrões preconizados para o seu sexo.

A luta das mulheres por esse direito durou mais, já que o acesso à formação superior era privilégio masculino. ${ }^{12}$ Somente em 1879, o Governo Imperial brasileiro formalizou o direito de as mulheres estudarem nesse nível de ensino, o que, obviamente, não foi suficiente para garantir o acesso das mulheres aos cursos superiores. Se, de um lado, a possibilidade de ingresso em cursos de formação superior abria novas alternativas para a colocação de mulheres no mundo do trabalho, por outro, também impulsionava as críticas de setores mais conservadores da sociedade (CUNHA; SILVA, 2010). Nessa conjuntura, observamos que, mesmo as mulheres mais ricas tinham dificuldade de operacionalizar o direito à educação superior, uma vez que, para o ingresso nos cursos, necessitavam de autorização familiar. Exigia-se que apresentassem inúmeros documentos, além de atestado de boa conduta (ALVARENGA, 2018). Assim, afirma Hahner (1981, p. 73):

Muitos membros masculinos da elite esperavam que as mulheres da classe inferior entrassem para a força de trabalho, mas não suas próprias parentes [...]. Para as mulheres da classe inferior, esse "trabalho honesto" seria executado em "casas de família", isto é, nas casas dos brasileiros mais ricos. As mulheres da classe superior deveriam permanecer em suas próprias casas, supervisionando o trabalho das mulheres mais pobres, $\mathrm{e}$ não tentar entrar nas profissões seguidas pelos homens de sua própria classe.

Dessa forma, não é de se estranhar que a primeira graduação feminina em instituição brasileira tenha ocorrido 79 anos após a fundação da primeira instituição de ensino superior no Brasil. De família abastada, branca, Maria Rita Lobato graduou-se na Faculdade de Medicina da Bahia em 1887 (ROSEMBERG, 2013). ${ }^{13}$

12 No Espírito Santo, somente em 1929/1930 é que ocorreu a abertura do primeiro curso superior.

${ }^{13}$ A primeira mulher negra a graduar-se, Maria Rita de Andrade, em 1926, isto é, 29 anos depois da primeira mulher branca (ROSEMBERG, 2013), também ilustra as interseções de classe e 
Hahner (1981) identifica um duplo obstáculo ao acesso à formação superior para as mulheres brasileiras nos anos finais do século XIX: a pressão e desaprovação social e a dificuldade financeira para arcarem com os custos da educação secundária. Esse contexto retardou por anos o acesso das professoras ao ensino superior. Araújo (2016) considera que o ingresso das mulheres na docência no ensino superior ocorreu por volta da década de 1970 e foi se intensificando e consolidando especialmente na segunda metade da década de 1980. Nesse período, ocorreu um considerável aumento de professoras mulheres em algumas universidades do país. Para a autora, as mudanças sociais e políticas desse período contribuíram para a ampliação dos

[...] horizontes femininos, propiciando a expansão da sua escolaridade e ingresso na universidade, viabilizando o acesso a novas oportunidades. Além disso, pressões de movimentos feministas e o crescimento da indústria no país corroboraram para impulsionar as mulheres pela busca por seu espaço no mercado de trabalho (ARAÚJO, 2016, p. 1).

Essas informações nos permitem inferir que a tardia inserção das mulheres como alunas em cursos superiores e a sua inserção mais efetiva em cursos associados ao cuidado, a assistência e à educação, sejam algumas das razões para que a docência feminina nas universidades brasileiras ainda seja inferior à docência masculina, em especial se observadas as áreas de Exatas. Essa "visita" à trajetória do acesso das mulheres à profissão docente ajuda-nos a compreender o fato de a universidade, como instituição parte da sociedade, também ser impactada por essas desiguais formas de sociabilidade entre homens e mulheres. A universidade, como instituição formadora de excelência, não pode se furtar de colocar essa questão em evidência e buscar formas de, cotidianamente, reduzir as desigualdades sociais de gênero, especialmente quando essas se tornam uma questão social (NETTO, 2012).

Por outro lado, quando analisamos as metas de ação afirmativa da ONU e da Unesco, vemos que o Brasil é um país considerado pioneiro dentre os que conseguiram alcançar uma maior aproximação à igualdade de acesso ao mais alto nível de educação formal das mulheres. Os dados estão disponíveis na base de Currículos Lattes (Capes/CNPQ), ilustrados na Tabela 1 a seguir:

raça/etnia presentes nas relações de gênero. 
Tabela 1 - Mestres/as e doutores/as, por sexo, no Brasil.

\begin{tabular}{|c|c|c|c|c|}
\hline \multirow{2}{*}{ Referência } & \multicolumn{2}{|c|}{ Doutorado } & \multicolumn{2}{c|}{ Mestrado } \\
\cline { 2 - 5 } & \multicolumn{2}{|c|}{ Pesquisa e ensino } & \multicolumn{2}{c|}{ Pesquisa e ensino } \\
\cline { 2 - 5 } & $\mathbf{N}^{\mathbf{0}}$ & $\%$ & $\mathbf{N}^{\mathbf{0}}$ & $\%$ \\
\hline Feminino & 63.853 & $47,50 \%$ & 44.337 & $53,21 \%$ \\
\hline Masculino & 70.567 & $52,50 \%$ & 38.984 & $46,79 \%$ \\
\hline Total & 134.420 & $100,00 \%$ & 83.321 & $100,00 \%$ \\
\hline
\end{tabular}

Fonte: Extração de dados da base de Currículos Lattes (Capes/CNPQ) em 30-11-2016.

Observa-se que a diferença de titulação de doutores/as por sexo é de $5 \%$ a mais para os homens. Em relação aos mestres, as mulheres são maioria entre os docentes. Por outro lado, também fica evidente que a diferença entre homens e mulheres está menor em relação aos anos anteriores.

Em relação à produção do conhecimento e à representatividade de mulheres docentes, um dado importante a se destacar é a influência do crescimento das discussões de gênero nas universidades, fomentadas em grande medida pelos grupos de estudos e pesquisas em gênero e sexualidade. Em sua tese de doutorado, Unbehaum (2014) aponta um crescimento no número de grupos de pesquisas na área da educação, registrados no Diretório de Grupos de Pesquisa do CNPq, a partir de 1992, quando esse Diretório foi criado. Em 1993, o CNPq contava com 201 grupos de pesquisa e, em 2010, já eram 2.236 grupos. Esse movimento acadêmico-científico, além de demonstrar um aumento de grupos na área da educação, expressa também o crescimento dos grupos que pesquisam gênero, que apresentam picos de crescimento entre os anos de 2008 e 2012. Unbehaum (2014) citou em sua tese a existência de 221 grupos que pesquisam gênero.

Esse crescimento na institucionalização dos grupos, que ocorreu não apenas no campo da educação, influencia e é influenciado pelas políticas afirmativas adotadas pelo Governo Federal, principalmente entre os anos de 2003 e 2016, o que demonstra a consolidação do campo de estudos de gênero (SILVA, 2021). Assim, os debates nas universidades acabam perpassando a formação docente para além da inicial, como as formações ofertadas pelos municípios e estados por ocorrência de discussão dos currículos, congressos, seminários, palestras etc. A práxis pedagógica, nesse sentido, também é afetada, ainda que movida por um processo reflexivo lento e complexo.

A Ufes, conforme pesquisa parametrizada no CnPQ (2020), tem 24 grupos que estudam a temática gênero, ainda que de forma transversal, distribuídos 
em três grandes áreas: 13 cadastrados nos eixos das Ciências Humanas, 7 na área da Linguística, Letras e Artes e 4 em Ciências Sociais e Aplicadas.

Os dados apresentados demonstram um avanço na participação das mulheres no ensino e pesquisa em nível nacional, mas também demonstram a persistência de algumas desigualdades por percursos sexuados associados à naturalização das habilidades ou capacidades femininas muito associadas ao cuidado, à assistência e a educação. A seguir, buscamos compreender como esses avanços, deslocamentos e persistências em relação às desigualdades de gênero perpassam os espaços de representatividade na Ufes.

\section{Gênero e trabalho docente no ensino superior: avanços, rupturas e continuidades e a experiência na UFES}

Os estudos realizados por Camacho (1997, p. 94), na década de 1990, já demonstravam que, embora a carreira do magistério fosse " [...] considerada uma atividade tipicamente feminina, nas Instituições Federais de Ensino Superior (IFES) brasileiras, 65\% dos docentes [eram] homens e 35\% mulheres". Na Ufes, lócus de estudo de Camacho, o corpo docente era, na ocasião da pesquisa, composto por 685 (68\%) homens e 325 (32\%) mulheres.

Ao relacionarmos a participação das mulheres (como docentes) no ensino superior e nos demais níveis de ensino, ${ }^{14}$ verificamos que, quanto mais "elevado" é o nível de ensino, menos mulheres ocupam a condição de docentes. O autor atribui essa inversão "[...] ao fato de que o salário e as condições de trabalho nas universidades públicas [são] significativamente melhores do que a situação verificada no primeiro e no segundo grau" (CAMACHO, 1997, p. 97).

Camacho (1997) é contundente ao afirmar que a "majoritariedade" dos homens, em relação às mulheres nas universidades, pode ser considerada como mais um aspecto da discriminação e subordinação das mulheres. No entanto, conforme Saffioti e Vargas (1994, p. 57), “[...] ter participação majoritária feminina no corpo docente não significa, porém, escapar às discriminações sexistas do mercado de trabalho". Desde a década de 1990, as autoras demonstram que a discriminação sexista se apresenta no magistério por meio de dois indicadores principais: a distribuição diferenciada dos/as docentes pelas etapas e pelas modalidades de ensino e a distribuição dos salários. $\mathrm{O}$

\footnotetext{
14 Séries iniciais do ensino fundamental $(95,8 \%)$, séries finais do ensino fundamental $(83,7 \%)$ e ensino médio $(74,1 \%)$ de mulheres atuando como docentes (CAMACHO, 1997).
} 
modo como essa distribuição se configura nos cotidianos escolares fortalece a tese de que, mesmo em um universo composto por maioria feminina, cabem aos homens os postos mais elevados de liderança, repercutindo, assim, tanto em prestígio social quanto em melhores salários.

Outro destaque de Camacho (1997) referente à questão de gênero nas universidades brasileiras é a sub-representação a que as mulheres estão sujeitas nessas instituições, uma vez que ainda ocupam um número consideravelmente menor que o dos homens nos altos órgãos de direção. Focalizando essa análise na Ufes, Camacho (1997) aponta, ainda, que, das 18 Vice-Reitorias, apenas uma $(5,55 \%)$ era dirigida por pessoa do sexo feminino. Em relação à direção de centros, cinco $(17,24 \%)$ de 29 eram ocupadas por mulheres e, nas chefias de departamento, 21 (47,72\%) mulheres e $23(52,27 \%)$ homens.

Essa realidade, desde a pesquisa realizada por Camacho (1997), sofreu alguns deslocamentos interessantes do ponto de vista quantitativo, se analisada na atualidade, ou seja, junho de 2020. Vale destacar que esse deslocamento se dá também sobre as condições gerais da universidade: aumento no número de cursos ofertados na graduação e pós-graduação, gerando aumento nos números gerais da comunidade acadêmica da Ufes: docentes, funcionários/as ou estudantes.

Do ponto de vista administrativo, houve uma reestruturação, havendo uma concentração dos órgãos da Ufes, em um nível estratégico, ${ }^{15}$ como as denominadas à época de Vice-Reitorias, que passaram a ser chamadas de PróReitorias. Atualmente, são apenas sete. ${ }^{16}$ Os Centros de Ensino são apenas $10^{17}$ na atualidade, além de uma Superintendência de Ensino a Distância.

15 Conforme o Plano de Desenvolvimento Institucional (2015- 2019), “No Nível Estratégico encontram-se, [...] os Conselhos Superiores (responsáveis pela deliberação das questões precípuas da Ufes); a Reitoria; as Pró-Reitorias; os Centros e as Secretarias (responsáveis por criar um planejamento do que será feito ao longo das gestões futuras); e os Órgãos Suplementares (responsáveis por dar a complementaridade necessária para o bom andamento das ações). No Nível Tático encontram-se os Departamentos Administrativos e os Acadêmicos. Sua tarefa é desenvolver um pensamento de como as estratégias já formadas pelas instâncias superiores serão aplicadas. Já o Nível Operacional, o último nível de planejamento, será responsável pelo desdobramento das ações do Nível Tático, em tarefas, ou seja, pela execução propriamente dita. Fazem parte desse nível de planejamento as Divisões, Seções e Coordenadorias" Disponível em: http://proplan.ufes.br/sites/proplan.ufes.br/files/field/anexo/pdi_-_2015-2019_1.88mb_.pdf. Acesso em: 26 jun. de 2020)

16 Pró-Reitoria de Planejamento e Desenvolvimento, Pró-Reitoria de Graduação, Pró-Reitoria de Extensão, Pró-Reitoria de Administração, Pró-Reitoria de Pesquisa e Pós-graduação, Pró-Reitoria de Gestão de Pessoas, Pró-Reitoria de Assuntos Estudantis e Cidadania.

${ }^{17}$ Centro de Ciências Jurídicas e Econômicas, Centro de Educação, Centro de Educação Física e Desportos, Centro Tecnológico, Centro de Artes, Centro de Ciências Humanas e Naturais, Centro de Ciências Agrárias, Centro Universitário Norte do Espírito Santo, Centro de Ciências Exatas, 
No que diz respeito às Pró-Reitorias, observamos que, das sete existentes, três $(42,85 \%)$ são dirigidas por mulheres e quatro $(57,15 \%)$ por homens. Das 11 direções de centros de ensino, apenas quatro (36,36\%) são ocupadas por mulheres: o Centro de Ciências Agrárias e Engenharias (CCAE) e o Centro de Ciências Exatas, Naturais e da Saúde (CCENS), ambos pertencentes ao campus de Alegre no sul do estado; o Centro de Ciências da Saúde (CCS) e o Centro de Artes (CAR), localizados no campus de Goiabeiras em Vitória.

Vale lembrar que a Superintendência de Ensino a Distância também é coordenada por uma professora. O Centro de Educação era, até meados de 2020, dirigido por uma mulher que deixou o cargo para assumir a Pró-Reitoria de Graduação (Prograd), ambos os espaços têm uma cultura de serem chefiados por mulheres na Ufes. De qualquer forma, merece destaque o fato de que, atualmente, as direções dos centros CCAE, CCENS e CCS (Campus Alegre) sejam ocupados por mulheres, uma vez que, historicamente, são campos de conhecimento majoritariamente liderados por homens. Essas "anomalias"18 nos indicam, entre outros elementos, que as mudanças são possíveis, ainda que lentas.

Valendo-nos do Censo da Educação Superior 2018 (INSTITUTO NACIONAL DE ESTUDOS E PESQUISAS EDUCACIONAIS ANÍSIO TEIXEIRA, 2019), observamos que, no país, dos $397.893^{19}$ docentes de instituições desse nível de ensino, 213.814 (53,74 \%) são homens e 184.079 $(46,26 \%)$ são mulheres. Os dados desse Censo demonstram também que, nos últimos anos, houve uma considerável redução na diferença do quantitativo de homens e mulheres na docência nesse nível, o que indica, também, a característica mutável e socialmente constituída do fenômeno analisado.

Nesse sentido, podemos inferir que, felizmente, tanto a luta das mulheres por melhores condições de salário e valorização profissional como o esforço delas para ampliar as possibilidades de formação acadêmica nas últimas décadas começam a aparecer nas estatísticas educacionais, embora haja diferenças de ocupação feminina mesmo em áreas específicas do conhecimento: as mulheres estão mais presentes na Engenharia Química do que na Engenharias Elétrica e Mecânica. Freitas (2013) indica um crescimento

Centro de Ciências da Saúde.

18 Termo utilizado na teorização de Ginzburg (2010). Para o autor, a anomalia, o excepcional, de certa forma nos indica o que é considerado "normal". Ela nos provoca o estranhamento que, tomado como ferramenta metodológica, nos ajuda a compreender a realidade muitas vezes escamoteada, pela suporta normalidade.

${ }^{19}$ Contabilizados os/as docentes em exercício e os/as afastados/as. 
da presença das mulheres na pesquisa e pós-graduação, no entanto as dissimetrias ainda são visíveis em todas as áreas, mesmo as feminizadas, como o campo da educação.

Utilizando novamente os dados do Lattes, é possível observar na Tabela 2 que as mulheres se concentram mais nas áreas de saúde, ciências humanas e ciências sociais aplicadas. Juntas correspondem a 43,64\%. Destaque para o fato de 16, 7\% estarem na área de ciências biológicas.

Tabela 2 - Distribuição de doutores/as, por sexo, nas grandes áreas segundo dados da Capes/CNPQ

\begin{tabular}{|l|c|c|c|c|}
\hline \multirow{2}{*}{\multicolumn{1}{|c|}{ Referências }} & \multicolumn{2}{c|}{ Feminino } & \multicolumn{2}{c|}{ Masculino } \\
\cline { 2 - 5 } & $\mathbf{N}^{\mathbf{0}}$ & $\mathbf{\%}$ & $\mathbf{N}^{\mathbf{0}}$ & $\mathbf{\%}$ \\
\hline Ciências Agrárias & 3.988 & $8,55 \%$ & 4.036 & $8,61 \%$ \\
\hline Ciências Biológicas & 7.542 & $16,17 \%$ & 4.700 & $10,03 \%$ \\
\hline Ciências da Saúde & 8.303 & $17,80 \%$ & 6.308 & $13,46 \%$ \\
\hline Ciências Exatas e da Terra & 4.210 & $9,03 \%$ & 7.735 & $16,50 \%$ \\
\hline Ciências Humanas & 7.976 & $17,10 \%$ & 5.711 & $12,18 \%$ \\
\hline Ciências Sociais Aplicadas & 4.078 & $8,74 \%$ & 5.539 & $11,81 \%$ \\
\hline Engenharias & 2.010 & $4,31 \%$ & 5.287 & $11,28 \%$ \\
\hline Linguística, Letras e Artes & 3.051 & $6,54 \%$ & 1.716 & $3,66 \%$ \\
\hline Não informado & 5.422 & $11,63 \%$ & 5.793 & $12,36 \%$ \\
\hline Outra & 58 & $0,12 \%$ & 57 & $0,12 \%$ \\
\hline Total & $\mathbf{4 6 . 6 3 8}$ & $\mathbf{1 0 0 , 0 0 \%}$ & $\mathbf{4 6 . 8 8 2}$ & $\mathbf{1 0 0 , 0 0 \%}$ \\
\hline
\end{tabular}

Fonte: Extração de dados da base de Currículos Lattes em 30-11-2016.

$\mathrm{Na}$ Ufes, uma expressão das dissimetrias de gênero presente na pósgraduação é o fato de que, dos 64 programas de pós-graduação da universidade, apenas 25 (39\%) cursos são coordenados por mulheres. É fato que temos avançado e provocado deslocamentos nas formas de ocupação, mas é fato também que muito há ainda a superar.

Certamente muitas outras dissimetrias estão presentes nesse campo, e, às vezes, assumem um grau de sutileza tão forte que se naturalizam até mesmo aos olhos das pessoas mais atentas. Exemplo disso é que parece muito natural que mulheres cientistas e pesquisadoras que são mães de filhos/as pequenos reduzam sua produção ou até deixem de comparecer a eventos científicos por não terem equipamentos sociais e coletivos que acolham a sua condição (STANISCUASKI, 2020). 
Focalizando esses dados no Espírito Santo, observamos que, dos 7.138 professores/as em nível superior, 56,06\% são homens e 43,94\% são mulheres seguindo a mesma tendência geral brasileira de ampliação do percentual de mulheres atuantes nessa etapa da educação. Dados da Pró-Reitoria de Gestão de Pessoas (Progep), de junho de 2020, mostram a distribuição de docentes da Ufes por sexo, formação e vínculo aos centros de ensino, conforme ilustra a Tabela 3:

Tabela 3 - Distribuição de docentes da Ufes por sexo e por formação, conforme vínculo aos centros de ensino

\begin{tabular}{|c|c|c|c|c|c|c|c|c|c|c|c|}
\hline \multirow{2}{*}{ Centro } & \multirow{2}{*}{ Sexo } & \multicolumn{2}{|c|}{ Ens. Sup. } & \multicolumn{2}{|c|}{ Especialização } & \multicolumn{2}{|c|}{ Mestrado } & \multicolumn{2}{|c|}{ Doutorado } & \multicolumn{2}{|c|}{ Total } \\
\hline & & $\mathrm{N}$ & $\%$ & $\mathrm{~N}$ & $\%$ & $\mathrm{~N}$ & $\%$ & $\mathrm{~N}$ & $\%$ & $\mathrm{~N}$ & $\%$ \\
\hline \multirow{3}{*}{ CAR } & Feminino & 4 & $50,00 \%$ & 1 & $100,00 \%$ & 10 & $38,46 \%$ & 46 & $44,66 \%$ & 61 & $44,20 \%$ \\
\hline & Masculino & 4 & $50,00 \%$ & 0 & $0,00 \%$ & 16 & $61,54 \%$ & 57 & $55,34 \%$ & 77 & $55,80 \%$ \\
\hline & Total & 8 & $100,00 \%$ & 1 & $100,00 \%$ & 26 & $100,00 \%$ & 103 & $100,00 \%$ & 138 & $100,00 \%$ \\
\hline \multirow{3}{*}{ CCAE } & Feminino & 1 & $33,33 \%$ & 0 & $0,00 \%$ & 1 & $33,33 \%$ & 47 & $40,52 \%$ & 49 & $40,16 \%$ \\
\hline & Masculino & 2 & $66,67 \%$ & 0 & $0,00 \%$ & 2 & $66,67 \%$ & 69 & $59,48 \%$ & 73 & $59,84 \%$ \\
\hline & Total & 3 & $100,00 \%$ & 0 & $0,00 \%$ & 3 & $100,00 \%$ & 116 & $100,00 \%$ & 122 & $100,00 \%$ \\
\hline \multirow{3}{*}{ CCE } & Feminino & 0 & $0,00 \%$ & 0 & $0,00 \%$ & 1 & $20,00 \%$ & 26 & $21,49 \%$ & 27 & $21,43 \%$ \\
\hline & Masculino & 0 & $0,00 \%$ & 0 & $0,00 \%$ & 4 & $80,00 \%$ & 95 & $78,51 \%$ & 99 & $78,57 \%$ \\
\hline & Total & 0 & $0,00 \%$ & 0 & $0,00 \%$ & 5 & $100,00 \%$ & 121 & $100,00 \%$ & 126 & $100,00 \%$ \\
\hline \multirow{3}{*}{ CCENS } & Feminino & 1 & $50,00 \%$ & 0 & $0,00 \%$ & 11 & $44,00 \%$ & 48 & $48,98 \%$ & 60 & $48,00 \%$ \\
\hline & Masculino & 1 & $50,00 \%$ & 0 & $0,00 \%$ & 14 & $56,00 \%$ & 50 & $51,02 \%$ & 65 & $52,00 \%$ \\
\hline & Total & 2 & $100,00 \%$ & 0 & $0,00 \%$ & 25 & $100,00 \%$ & 98 & $100,00 \%$ & 125 & $100,00 \%$ \\
\hline \multirow{3}{*}{ CCHN } & Feminino & 2 & $50,00 \%$ & 1 & $25,00 \%$ & 6 & $35,29 \%$ & 108 & $49,54 \%$ & 117 & $48,15 \%$ \\
\hline & Masculino & 2 & $50,00 \%$ & 3 & $75,00 \%$ & 11 & $64,71 \%$ & 110 & $50,46 \%$ & 126 & $51,85 \%$ \\
\hline & Total & 4 & $100,00 \%$ & 4 & $100,00 \%$ & 17 & $100,00 \%$ & 218 & $100,00 \%$ & 243 & $100,00 \%$ \\
\hline \multirow{3}{*}{ CCJE } & Feminino & 3 & $42,86 \%$ & 4 & $57,14 \%$ & 13 & $44,83 \%$ & 80 & $47,62 \%$ & 100 & $47,39 \%$ \\
\hline & Masculino & 4 & $57,14 \%$ & 3 & $42,86 \%$ & 16 & $55,17 \%$ & 88 & $52,38 \%$ & 111 & $52,61 \%$ \\
\hline & Total & 7 & $100,00 \%$ & 7 & $100,00 \%$ & 29 & $100,00 \%$ & 168 & $100,00 \%$ & 211 & $100,00 \%$ \\
\hline \multirow{3}{*}{ CCS } & Feminino & 10 & $83,33 \%$ & 4 & $36,36 \%$ & 22 & $55,00 \%$ & 180 & $64,06 \%$ & 216 & $62,79 \%$ \\
\hline & Masculino & 2 & $16,67 \%$ & 7 & $63,64 \%$ & 18 & $45,00 \%$ & 101 & $35,94 \%$ & 128 & $37,21 \%$ \\
\hline & Total & 12 & $100,00 \%$ & 11 & $100,00 \%$ & 40 & $100,00 \%$ & 281 & $100,00 \%$ & 344 & $100,00 \%$ \\
\hline \multirow{3}{*}{$\mathrm{CE}$} & Feminino & 2 & $66,67 \%$ & 0 & $0,00 \%$ & 2 & $40,00 \%$ & 57 & $64,04 \%$ & 61 & $62,89 \%$ \\
\hline & Masculino & 1 & $33,33 \%$ & 0 & $0,00 \%$ & 3 & $60,00 \%$ & 32 & $35,96 \%$ & 36 & $37,11 \%$ \\
\hline & Total & 3 & $100,00 \%$ & 0 & $0,00 \%$ & 5 & $100,00 \%$ & 89 & $100,00 \%$ & 97 & $100,00 \%$ \\
\hline \multirow{3}{*}{ CEFD } & Feminino & 2 & $66,67 \%$ & 0 & $0,00 \%$ & 3 & $37,50 \%$ & 18 & $41,86 \%$ & 23 & $42,59 \%$ \\
\hline & Masculino & 1 & $33,33 \%$ & 0 & $0,00 \%$ & 5 & $62,50 \%$ & 25 & $58,14 \%$ & 31 & $57,41 \%$ \\
\hline & Total & 3 & $100,00 \%$ & 0 & $0,00 \%$ & 8 & $100,00 \%$ & 43 & $100,00 \%$ & 54 & $100,00 \%$ \\
\hline \multirow{3}{*}{ CEUNES } & Feminino & 4 & $66,67 \%$ & 0 & $0,00 \%$ & 7 & $36,84 \%$ & 75 & $41,21 \%$ & 86 & $41,55 \%$ \\
\hline & Masculino & 2 & $33,33 \%$ & 0 & $0,00 \%$ & 12 & $63,16 \%$ & 107 & $58,79 \%$ & 121 & $58,45 \%$ \\
\hline & Total & 6 & $100,00 \%$ & 0 & $0,00 \%$ & 19 & $100,00 \%$ & 182 & $100,00 \%$ & 207 & $100,00 \%$ \\
\hline \multirow{3}{*}{$\mathrm{CT}$} & Feminino & 1 & $33,33 \%$ & 0 & $0,00 \%$ & 2 & $14,29 \%$ & 45 & $29,80 \%$ & 48 & $28,24 \%$ \\
\hline & Masculino & 2 & $66,67 \%$ & 2 & $100,00 \%$ & 12 & $85,71 \%$ & 106 & $70,20 \%$ & 122 & $71,76 \%$ \\
\hline & Total & 3 & $100,00 \%$ & 2 & $100,00 \%$ & 14 & $100,00 \%$ & 151 & $100,00 \%$ & 170 & $100,00 \%$ \\
\hline \multirow{3}{*}{ Total } & Feminino & 30 & $58,82 \%$ & 10 & $38,46 \%$ & 78 & $40,84 \%$ & 730 & $46,50 \%$ & 848 & $46,14 \%$ \\
\hline & Masculino & 21 & $41,18 \%$ & 16 & $61,54 \%$ & 113 & $59,16 \%$ & 840 & $53,50 \%$ & 990 & $53,86 \%$ \\
\hline & Total & 51 & $100,00 \%$ & 26 & $100,00 \%$ & 191 & $100,00 \%$ & 1570 & $100,00 \%$ & 1838 & $100,00 \%$ \\
\hline
\end{tabular}

Fonte: Dados obtidos junto à Progep, referentes ao ano de 2020. 
Como esperado, os dados evidenciam a permanência das desigualdades de gênero por territórios, no qual os cursos culturalmente associados à educação, assistência e saúde recebem mais mulheres como docentes; e os cursos vinculados à tecnologia e às ciências exatas são compostos majoritariamente por homens. Esses dados refletem, em grande medida, o cultural e histórico papel social atribuído a homens e a mulheres em nossa sociedade. Observamos que desde crianças as meninas são influenciadas, implícita e explicitamente, a se familiarizarem com as atividades socialmente atribuídas às mulheres na vida adulta, como o cuidado e a realização das atividades domésticas. Da mesma forma, os meninos são incentivados a agirem de acordo com o que socialmente se espera de um homem adulto. Nesse sentido, deve-se questionar em que medida os processos de socialização das crianças e jovens interferem na escolha da profissão e, obviamente, no curso superior a cursar.

Deve-se considerar os desafios cotidianos vividos pelas professoras que exercem docência em cursos ocupados majoritariamente por homens. Um desses desafios é o assédio sofrido pelas professoras, em especial o moral e o sexual. Sobre isso vale lembrar que, impulsionado pelo crescimento de denúncias de assédio moral e sexual, universidades federais, estaduais e municipais, institutos federais e Cefet, o Sindicato Nacional dos Docentes das Instituições de Ensino Superior (ANDES-SN), definiu o dia 17 de outubro como um dia nacional de luta da categoria. De acordo com o sindicato, "[...] a data foi incluída no calendário do Sindicato Nacional, em 2018, durante o $37^{\circ}$ Congresso da entidade. Naquele ano, em decisão congressual, foi reforçada a necessidade da implementação de comissões e ouvidorias nas universidades para apuração dos casos [...]". Heloani $\left(2004^{20}{ }^{2}\right.$, apud ANDES, 2017) afirma que o ambiente em que o assédio mais tem crescido no Brasil é o acadêmico, provavelmente pela intensificação nos últimos anos do que a autora chama de hipercompetição. Esse fenômeno acirra disputas por melhores postos acadêmicos. A autora salienta ainda que a inserção de grupos minoritários, que historicamente ficavam às margens da academia, potencializou a hipercompetição. Nesse sentido, o assédio se constitui como uma ferramenta de disputa.

O território feminilizado e feminizado se evidencia nos dados do Centro de Educação (CE) com 62,89\% de mulheres e 37, 11\% de homens, e do Centro de Ciências da Saúde (CCS) com 62,79\% de mulheres e 37,21\% de homens - de

${ }^{20}$ Para saber mais, consulte: HELOANI, R. Assédio moral: um ensaio sobre a expropriação da dignidade do trabalho. ERA-eletrônica, v. 3, n. 1, Art. 10, jan./jun.2004. Disponível em www.rae.com.br/eletrônica/index.cfm. 
áreas que lidam com o cuidado - em relação aos dados do Centro Tecnológico (CT) com 28, 24\% de mulheres e 71,76\% de homens, e do Centro de Ciências Exatas (CCE) com 21,43\% de mulheres e 78,57\% de homens. Notamos também que, à exceção do CE e do CCS, em todos os demais centros os homens são mais qualificados em doutorado do que as mulheres.

Nessa lógica de problematizar a guetização, é preciso pensar as ocupações de cargos de chefia por um recorte de gênero, perguntando: quais cargos são historicamente ocupados por homens e por mulheres? Quem assume historicamente as Pró-Reitorias de Graduação (Prograd), de Extensão (Proex), de Pós-Graduação (PRPPG) e de Planejamento (Proplan)? Quem tem ocupado historicamente a Reitoria? Em verdade, esta última é bastante evidente, pois nunca tivemos uma mulher reitora na Ufes. Em que pese a eleição de uma mulher (Profa. Dra. Ethel Maciel) para a Reitoria no ano de 2020, essa foi impedida de ser empossada pela política ideologicamente orientada no governo de Jair Messias Bolsonaro (2019).

Não é apenas no âmbito doméstico que as mulheres são expostas à situação de desigualdade e de violência. Elas podem ser atingidas em diferentes espaços, e a universidade tem se mostrado um local no qual persistem as desigualdades que se expressam por meio da violência institucional, do assédio moral e, inclusive, sexual. De forma similar, também as mulheres lésbicas e bissexuais sofrem diversos tipos de violência em função de sua orientação sexual e identidade de gênero no ambiente da universidade. No caso das transexuais, que se tornam alvos de preconceitos e agressões múltiplas, normalmente isso tem levado ao abandono dos estudos e até de cargos.

Nesse sentido, a Ufes criou, em 2016, um canal na Ouvidoria que recebe denúncia de mulheres sobre as mais diversas situações de violências, como assédios ou agressões. Desde a sua criação, professoras, servidoras e alunas denunciam casos de assédio sexual, que ora estão afetos à relação alunasalunos, mas não raro ocorre de professores para alunas ou de alunos para professoras. No entanto, ainda há muita preocupação, principalmente das acadêmicas, com a retaliação por parte de professores, como relatado recentemente em reunião ocorrida na Ouvidoria, Reitoria e Comissão de Direitos Humanos (UNIVERSIDADE FEDERAL DO ESPÍRITO SANTO, 2018).

Mas, também podemos observar, no movimento constante das correlações de forças na sociedade e na universidade, como instituição parte desta sociedade, que a Ufes tem atualmente 1.838 docentes na função de magistério 
do ensino superior. Desse total, $46,14 \%$ são mulheres ${ }^{21}$ e $53,86 \%$ são homens. Ao comparamos esses dados aos apresentados por Camacho em 1997, quando $68 \%$ dos docentes eram homens e 32\% eram mulheres, notamos um considerável crescimento da participação das mulheres no corpo docente da Ufes, o que, mais numa vez, coaduna com as informações extraídas do Censo da Educação Superior 2018. Essa descontinuidade numérica, certamente também representa um avanço dos debates relacionados ao gênero que vivenciamos no Brasil, nas últimas décadas.

Mas, independentemente da quantidade de mulheres, devemos refletir sobre a qualidade da participação e permanência no espaço universitário. Maffia (2002) já destacava que o grande problema não era a quantidade de participação a priori de mulheres e homens, mas outros argumentos que sustentam e atravessam o acesso, a permanência e a ocupação dos cargos de liderança e de gestão no âmbito acadêmico.

Diante dos dados expostos, vale questionar: se os processos de seleção (de cargos temporários e efetivos) de professores/as é aberto e formalmente não limita as inscrições quanto ao sexo, que fatores ainda impulsionam esses dados? Inferimos que a constituição patriarcal e sexista da sociedade brasileira, que, historicamente, delimita papéis socialmente aceitos para homens e mulheres, ainda tem forte influência sobre a escolha de que curso superior cursar e, consequentemente, sobre o exercício profissional.

A questão da política de acesso aos espaços de poder e aos territórios que culturalmente foram negados às mulheres faz parte histórica da agenda das suas lutas. A dificuldade de acesso das pessoas aos bens culturais da humanidade, inclusive à universidade, será tanto maior quanto maior forem essas desigualdades sociais e vice-versa. Nesse sentido, o acesso das mulheres à universidade precisa ser concebido em relação direta com as desigualdades sociais de classe, gênero ou raça/etnia. Se a dificuldade de inserção social se expressa na universidade, é porque as desigualdades se apresentam de forma ampla na sociedade, mas também porque há uma permanência na dificuldade de acesso a esse território.

As universidades federais, nos últimos anos, passaram a adotar o sistema de cotas sociais e raciais para acesso dos/as estudantes aos cursos de graduação e também estimulam as cotas para pessoas pretas nos cursos de pós-graduação. Em certa medida, buscam equilibrar as dinâmicas sociais causadoras dessas

21 Adotamos apenas a indicação de sexo biológico, pois é a que os dados obtidos informaram somente os/as docentes. Fato que identificamos como um limite no processo de armazenamento de informações relacionadas com o sexo, por parte da universidade. 
dificuldades de acesso. ${ }^{22}$ É preciso aqui considerar a necessidade de se articular as dimensões de classe social e de raça/etnia com as análises de gênero, uma vez que raça e etnia se constituem como marcadores determinantes para se pensar as políticas para a Ufes. Há uma alquimia de fenômenos que constituem as desigualdades. Nesse sentido, quando se cria uma política para um fenômeno, acaba-se tangenciando outros. Assim, as cotas sociais e raciais foram uma importante política de acesso também para as mulheres.

No entanto, quando se pensa em nível de acesso de docentes à universidade, não temos políticas específicas de gênero. Há a política de etnia/raça para concursos públicos (Lei $\mathrm{N}^{\circ}$. 12.990/2014), mas essa não tem recorte de gênero. Além disso, há a dificuldade que perpassa a implementação da lei em si, tendo em vista que os concursos nas universidades públicas são realizados de forma "fragmentada" em editais demandados pelos departamentos dos centros de ensino, geralmente com apenas uma vaga, o que impossibilita a aplicação das cotas. A mudança nesse processo implicaria que se fizessem concursos unificando todas as vagas existentes na universidade e a Reitoria promovesse um concurso amplo.

O aprofundamento da implantação de cotas sociais e étnico-raciais para pretos, pardos e indígenas (PPI) em programas de pós-graduação é uma medida que acreditamos, em longo prazo, beneficiará o acesso das mulheres negras aos concursos nas universidades públicas, como a Ufes. As cotas em programas de pós-graduação já são uma realidade nos cursos de Artes, Ciências Sociais, Comunicação e Psicologia da Ufes que aprovaram a reserva de vagas para negros/as, pardos/as e indígenas, a partir dos editais para as turmas de 2017. Entretanto, é preciso entender que as desigualdades de gênero, quando "combinadas" com outras desigualdades, resultam em formas múltiplas de violação de direitos das mulheres.

É importante destacar que os estudos sobre esse tema se dedicam a compreender a permanência de estudantes na educação, e não a dos/as professores/as. Mas, se considerarmos que a formação em curso superior é pressuposto para a atuação docente nesse nível de ensino, quanto mais mulheres tiverem acesso à formação superior e de pós-graduação, maior será a possibilidade de ocupação delas como docentes das IES. Dessa forma, a garantia de acesso e ocupação das mulheres no magistério superior está

${ }^{22}$ A Portaria $\mathrm{n}^{\circ}$ 545, de 16 de junho de 2020, revoga a Portaria Normativa MEC nº 13, de 11 de maio de 2016. 
intimamente relacionada com o acesso e a permanência das estudantes de graduação e pós-graduação.

Outra constatação das desiguais relações de gênero na Ufes refere-se à reduzida participação das mulheres em cargos de liderança. Notamos que, "[...] embora haja equilíbrio quantitativo entre os sexos, há poucas mulheres nos Conselhos da Ufes" (ADUFES, 2018, p. 5). A composição do Conselho Universitário é expressão das desigualdades quanto ao exercício da docência na Ufes (27,5\% da ocupação feminina e $72,5 \%$ masculina) e no Conselho de Ensino, Pesquisa e Extensão (Cepe) - composto por 38,5\% de mulheres e por 61,5\% de homens (ADUFES, 2018). No Conselho de Curadores (CCur), a diferença na distribuição por sexo é menor: $41,7 \%$ de mulheres ${ }^{23}$ e $58,1 \%$ de homens. O mesmo ocorre nos cargos de chefia: "[...] no geral, os cargos de gestão da Ufes (chefias de departamentos, colegiados e pró-reitorias) são ocupados por 142 mulheres, enquanto os homens ocupam 205 dos cargos. Desta forma, elas representam 40,9\%" (ADUFES, 2018, p. 5).

Os dados apresentados indicam que, apesar das conquistas visíveis das mulheres no ensino superior, conquistas estas que se manifestam na Ufes, ainda é preciso uma longa caminhada em busca da equidade entre homens e mulheres nesse tão importante espaço e tempo de formação, principalmente porque, como nos lembra Le Feuvre (2008, apud YANNOULAS, 2013b), apesar dos avanços das mulheres nas últimas duas décadas, a maior inserção das mulheres em territórios culturalmente masculinos se dá de forma ambígua e contraditória: "[...] O ingresso em territórios masculinos está caracterizado pelo alinhamento das mulheres à norma masculina" (p. 40).

Não menos importante é destacar os números ínfimos de professoras negras e a inexistência de professoras trans mulheres na Ufes. Em relação às mulheres negras, Silva (2013, p. 55) ressalta: “[...] a mulher negra carrega uma história de exploração no mundo do trabalho decorrente da escravidão que até nos dias atuais geram reflexos em suas carreiras profissionais".

Entendemos com Silva (2021) que é fundamental fortalecer a defesa pela igualdade substantiva. Isto porque a igualdade substantiva se move além da igualdade de oportunidades, exigindo mudança transformadora. Assim, busca a igualdade perante a lei, a de direito, a de fato, a de oportunidades também, mas fundamentalmente a de condições, a de trato e a de resultados. A igualdade de oportunidades seria aquela que posiciona todos os membros de uma sociedade nas mesmas condições de partida e lhes oferece iguais

${ }^{23}$ Inclusive é presidido por uma mulher, Sônia Maria Costa Barreto, representante da comunidade. 
possibilidades para participar e atuar em diversos âmbitos da sociedade. Já a igualdade de trato consistiria na igualdade de tratamento de todas as pessoas, independentemente de sexo, raça, idade, religião etc.; e a igualdade de resultados seria aquela que garantiria a todas as pessoas a igualdade quanto ao ponto de chegada em seus objetivos e áreas em que se inserem, bem como a obtenção dos mesmos benefícios das ações porventura implementadas (REEVES; BADEN, 2000).

\section{Considerações finais}

Neste texto, procuramos diversos elementos que possibilitam a reflexão sobre a representatividade das mulheres na Ufes. Realizamos um recorte panorâmico das relações sociais de gênero com foco nas mulheres tanto em aspectos quantitativos quanto qualitativos, para evidenciar e destacar o cenário das dissimetrias de gênero ainda presentes.

Optamos pelo método indiciário de pesquisa porque nos permite mapear as especificidades dos processos históricos complexos e heterogêneos que circunscrevem a atuação da mulher na nossa sociedade e nos possibilita um olhar sobre um contexto particular: a Ufes. Com essa finalidade, utilizamos dados de diversas instâncias da universidade, desde Pró-Reitorias até o Sindicato da Categoria dos/as Professores/as, para trazer à tona aspectos a serem considerados para refletirmos sobre as complexidades que perpassam o acesso, a permanência, a participação na pós-graduação e produção do conhecimento, bem como a possibilidade de ocupar os espaços de representação da instituição.

O estudo realizado demonstra que o processo de inserção das mulheres no magistério se deu alinhado aos pressupostos de gênero da sociedade brasileira, nitidamente patriarcal e sexista. Apesar dos avanços, as mulheres atravessam uma desigualdade tanto no espaço social quanto no espaço acadêmicocientífico. Isso pode ser percebido quando abordamos o histórico da participação das mulheres no ensino e, posteriormente, a inserção delas no ensino superior, observando os diferentes marcadores de classe social, formação etc. que configuraram processos educativos diferentes para as meninas/mulheres.

Notamos um aumento na participação das mulheres, embora ainda permaneça uma sub-representação, pois elas ocupam um número consideravelmente menor do que os homens nos altos órgãos de direção, em cargos de liderança, em Pró-Reitorias, nas coordenações de centros de ensino, 
Conselhos da universidade e de cursos de pós-graduação. Ademais, percebemos que, apesar desse aumento na participação, ainda existe uma distribuição desigual segundo as áreas de formação e/ou centros de ensino, reproduzindo estereótipos tradicionais de gênero, ou seja, as mulheres permanecem majoritariamente em cursos tradicionalmente feminizados. Os dados problematizados nos indicam que existem conquistas no ensino superior, rupturas importantes, mas ainda temos um longo caminha em busca da igualdade substantiva de gênero na docência do ensino superior. Essa tarefa torna-se ainda mais árdua quando consideramos os marcadores de raça/etnia.

Os debates de gênero continuam em crescimento e alguns deslocamentos têm sido evidentes em termos de acesso, de permanência, de produção acadêmica e participação nas instâncias de representação. Mas, ao falarmos das políticas de acesso aos espaços de poder na universidade, encontramos ainda uma dificuldade de inserção social, pois entendemos que as desigualdades se apresentam de forma ampla, mas também porque existe uma permanência nas dificuldades de acesso por parte das mulheres, já que não existe nenhuma política específica voltada às docentes nessa direção. No entanto, operamos na lógica de que, havendo mais acesso das mulheres ao ensino superior, maiores serão as possibilidades da presença delas nas instituições de ensino como docentes assim como a promoção de políticas específicas que fomentem a permanência e qualidade do trabalho das mulheres nas instituições de ensino. Assim, entendemos que devemos continuar a fomentar e promover ações que permitam dissipar essas desigualdades, sobretudo para pensarmos as ações empreendidas em nível institucional sobre as questões de raça/etnia e de gênero.

\section{Referências}

ANDES. Sindicato Nacional dos Docentes das Instituições de Ensino Superior.

(2020a). Cartilha: contra todas as formas de assédio, em defesa dos direitos das mulheres, das/os indígenas, das/os negras/os e dos LGBT. Disponivel em: https://issuu.com/andessn/docs/imp-doc346583622. Acesso em: 05 nov. 2021.

(2020b). 17 de outubro: Dia Nacional contra o Assédio Sexual e Moral nas Ifes, Iees e Imes. Disponivel em:

https://www.andes.org.br/conteudos/noticia /17-de-outubro-dia-nacional-contra-o- assedio-sexual-e-moral-nas-ifes-iees-eimes1/page:10/sort:Conteudo.created/directi on:desc. Acesso em: 05 nov. 2021.

ALVARENGA, Elda.

(2018). A inserção das mulheres no magistério capixaba: desdobramentos possíveis no trabalho docente no Estado do Espírito Santo (1845-1920). Tese de doutorado em Educação apresentada na Universidade Federal do Espírito Santo. Vitória. 
ARAÚJ0, Sabrina Sales.

(2016). A presença de docentes femininas no Ensino Superior no Brasil de 1990 a 2005. XIII Encontro Regional de História: História e democracia: possibilidades do saber histórico. Coxim/MS.

ARAUJ0, Samara Carla Lopes Guerra; YANNOULAS, Silvia Cristina.

(2020). Trabalho docente, feminização e pandemia. Revista Retratos da Escola, Brasília, v. 14, n. 30, p. 754-771, set./dez. 2020.

BARDIN, Laurence.

(2008). Análise de conteúdo. Lisboa, Edições 70.

BOBBI0, Norberto; MATTEUCCI, Nicola; PASQUIN0, Jeanfranco.

(1998). Dicionário de política. Brasília, Editora Universidade de Brasília.

BRASIL. PRESIDÊNCIA DA REPÚBLICA/ SECRETARIA ESPECIAL DE POLÍTICAS PARA A MULHER.

(2015). Plano Nacional de Política para as mulheres. Brasília.

CADERNO DE NOTÍCIAS. Jornal da ADUFES Associação dos Docentes da Universidade Federal do Espírito Santo.

(2018). Seção Sindical do Andes. Sindicato Nacional. Vitória, n. 92 p. 1-8, jan./fev./mar.

CONFERENNCIA NACIONAL DOS BISPOS DO BRASIL.

(2015). Nota da CNBB sobre a inclusão da ideologia de gênero nos Planos de Educação. Disponivel em:

http://www.cnbb.0rg.br/imprensa-

1/noticias/16732-cnbb-divulga-nota-sobre-ainclusao-da-ideologia-de-genero-nos-planosde-educacao. Acesso em: 10 jul. 2015.

CAMACH0, Thimoteo Mello.

(1997). Mulher, trabalho e poder. o machismo nas relações de gênero na UFES. Vitória: EDUFES.

CARRILH0, Anabelle.

(2013). A feminização na produção científica recente: um conceito difuso de compreensão necessária. In: Silvia Cristina Yannoulas (Org.).
Trabalhadoras: análise da feminização das profissões e ocupações. Brasília, Abaré, p. 281298.

CRENSHAW, Kimberlé W.

(2002). Documento para o encontro de especialistas em aspectos da discriminação racial relativos ao gênero. Estudos Feministas, 10 (1), p. 171-188.

CUNHA, Washington D. dos Santos; SILVA, Rosemaria J. Vieira.

(2010). A educação feminina do século XIX: entre a escola e a literatura. Gênero, Niterói, v. 11, n. 1, p. 97-106, 2. sem.

DURÃES, Sarah J. Alves.

(2002). Escolarização das diferenças: qualificação do trabalho docente e gênero em Minas Gerais (1860-1906). Tese de Doutorado em Educação apresentado na Pontifícia Universidade Católica de São Paulo, São Paulo.

FREITAS, Katia Siqueira de.

(2009). Alguns estudos sobre evasão e persistência de estudantes. Eccos-Rev. Cient., São Paulo, v. 11, n.1, p. 247-264, jan./jun.

FREITAS, Bárbara Bezerra.

(2013). Diferenças de gênero em pesquisa e pósgraduação em engenharia no Brasil. Dissertação de Mestrado apresentada no Centro Federal de Educação Tecnológica Celso Sucknow da Fonseca.

GINZBURG, Carlo.

(2007). O fio e os rastros: verdadeiro, falso e fictício. Tradução de Rosa Freire d'Aguiar e Eduardo Brandão. São Paulo: Editora Companhia das Letras.

GINZBURG, Carlo.

(2010). Sou obcecado pela prova. Folha de São Paulo, São Paulo, 2010, 28 de novembro de 2010. Entrevista concedida a Bernardo Carvalho.

GOMES, Helder.

(2012). Mulheres nos Mercados de Trabalho no Brasil recente. In: Elda Alvarenga; Erineusa. Maria da Silva; Penha Mara Fernandes (Org.). Estratégias metodológicas para a formação em 
gênero: possibilidades teóricas-práticas. Vitória, Coopemult Consultoria, p. 133-153.

HAHNER, June E.

(1981). A mulher brasileira e suas lutas sociais e políticas: 1850-1937. São Paulo: Brasiliense.

HIRATA, Helena.

(2014). Gênero, classe e raça: Interseccionalidade e consubstancialidade das relações sociais. Revista Tempo Social, São Paulo, v. 26, n. 1, p. 61-73.

HYPOLITO, Álvaro Moreira.

(2010). Processo de trabalho docente. In: Dalila Andrade Oliveira; Adriana Cancela Duarte; Lívia Fraga Vieira (org.). Dicionário: trabalho, profissão e condição docente. Belo Horizonte UFMG/Faculdade de Educação. 1 CD-ROM.

\section{INSTITUTO NACIONAL DE ESTUDOS E PESQUISAS} EDUCACIONAIS ANÍSIO TEIXEIRA.

(2019). Sinopse estatística da educação superior 2018. Brasília. Disponível em: http://portal.inep.gov.br/web/guest/sinopse s-estatisticas-da-educacao-superior. Acesso em: 28 jun. 2020.

\section{INSTITUTO BRASILEIRO DE GEOGRAFIA E ESTATISTICA.}

(2018). Pesquisa nacional por amostra de domicílios contínua: divulgação especial mulheres no mercado de trabalho. Disponivel em:

https://ftp.ibge.gov.br/Trabalho_e_Rendime nto/Pesquisa_Nacional_por_Amostra_de_Do micilios_continua/Estudos_especiais/Mulhere S_no_Mercado_de_Trabalho_2018.pdf. Acesso em: 05 nov. 2021.

KERGOAT, Danièle.

(2010). Dinâmica e consubstancialidade das relações sociais. Novos Estudos. Cebrap, 86, p. 93-103.

LOMBARDI, Maria Rosa.

(2013). Formação e docência em engenharia, na ótica do gênero: um balanço de estudos recentes e dos sentidos da feminização. In: Silvia Cristina Yannoulas (0rg.). Trabalhadoras: análise da feminização das profissões e ocupações. Brasília, Abaré, p. 111-136.
MARCONDES, Mariana Mazzini.

(2013). 0 cuidado na perspectiva da divisão sexual do trabalho: contribuições para os estudos sobre a feminização do mundo do trabalho. In: Silvia Cristina Yannoulas (Org.). Trabalhadoras: análise da feminização das profissões e ocupações. Brasília, Abaré, p. 251280.

MAFFIA, Diana.

(2002). Crítica feminista à ciência. In: Costa, A. A, A.; Sardenberg, C. M. B. (Org.). Feminismo, Ciência e Tecnologia. Salvador: REDOR/NEIMFFCH/UFBA. Coleção Bahianas, n. 8, p. 25-38.

\section{MÁTRIA.}

(2015). Publicação da Confederação Nacional dos Trabalhadores em Educação-CNTE. Brasília, v. 1, n. 13, p. 2-63, mar.

NASCIMENTO, Cecília Vieira.

(2011). Caminhos da docência: trajetórias de mulheres professoras em Sabará - Minas Gerais (1830-1880). Tese de Doutorado em Educação apresentado à Universidade Federal de Minas Gerais, Belo Horizonte.

NETTO, José Paulo.

(2012). A questão social na América Latina. In: Maria Lucia Teixeira Garcia; Eugenia Célia Raizer (Org.). A questão social e as políticas sociais no contexto latino-americana. Vitória, Edufes.

OLIVEIRA, Talita Santos de.

(2013). A inserção das mulheres na construção: um retrato midiático sobre a expressão e reprodução da feminilidade no setor. In: Silvia Cristina Yannoulas (Org.). Trabalhadoras: análise da feminização das profissões e ocupações. Brasília, Abaré, p. 137-158.

REEVES, Hazel; BADEN, Sally.

(2000). Gender and development. concepts and definitions. Brighton, Institute of Development Studies.

RIBEIRO, Arilda I. M.

(2011). Mulheres educadas na colônia. In: Eliane Marta Teixeira Lopes; Luciano Mendes de Faria Filho; Cynthia Greive Veiga (0rg.). 500 anos de 
educação no Brasil. Belo Horizonte, Autêntica, p. 79-94.

ROSEMBERG, Fúlvia.

(2013). Mulheres educadas e a educação das mulheres. In: Carla B. Pinsky; Joana M. Pedro. Nova história das mulheres no Brasil. São Paulo, Contexto, p. 333-359.

SAFFIOT, Heleieth I. B; VARGAS, Monica Muñoz. (1994). Mulher brasileira é assim. Rio de Janeiro: Rosa dos Ventos.

SCOT, Joan Wallach.

(1995). Gênero: uma categoria útil de análise histórica. Educação \& Realidade, Porto Alegre, v. 20, n. 2, p. 71-99.

SILVA, Erineusa Maria da; FERREIRA, Eliza Bartolozzi.

(2019). Os movimentos das professoras da educação básica na constituição das políticas de gênero na escola. Educação e Pesquisa, 45, e200235. Epub 16 de setembro.

SILVA, Erineusa Maria da.

(2021). O movimento pedagógico de gênero nas escolas: o que e como fazem as professoras? Curitiba, Appris.

SILVA, Maria de Lourdes.

(2013). Enfrentamento ao racismo e discriminação na educação superior: experiências de mulheres negras na construção da carreira docente. Tese (Doutorado) Universidade Federal de São Carlos, São Carlos - SP. Disponível em:

https://repositorio.ufscar.br/bitstream/handl e/ufscar/2314/5412.pdf?sequence $=1$. Acesso em: 22 jul. 2020.
STANISCUASKI, F. et. al.

(2020). Impacto do COVID-19 em mães acadêmicas. Sciencie. 15 de maio. v. 368, edição 6492, p. 724.

YANNOULAS, Silvia Cristina.

(2013a). Apresentação. In: Silvia Cristina Yannoulas (Org.). Trabalhadoras: análise da feminização das profissões e ocupações. Brasília, Abaré, p. 21-29.

YANNOULAS, Silvia Cristina.

(2013b). Sobre o que nós, mulheres, fazemos. In: Silvia Cristina Yannoulas (0rg.). Trabalhadoras: análise da feminização das profissões e ocupações. Brasília, Abaré, p. 31-65.

UNBEHAUM, Sandra.

(2014). As questões de gênero na formação inicial de docentes: tensões no campo da educação. Tese de Doutorado em Educação apresentado na Pontifícia Universidade Católica de São Paulo.

UNIVERSIDADE FEDERAL DO ESPÍRITO SANTO. (2018). Relatório final da $1^{a}$ Conferência de Ações Afirmativas/UFES. Políticas afirmativas e saberes das diferenças: Avaliação da Trajetória de uma Década e Construção de uma Agenda Propositiva. Vitória, UFES.

\section{Recebido em}

novembro de 2020

\section{Aprovado em}

novembro de 2021 